\title{
Досвід застосування стандартів консенсусу Американської тиреоїдної асоціації в клініці загальної хірургії на базі .ьвівської клінічної лікарні на ЗТ ПАТ “Українська залізниця” філії “Центр охорони здоров'я"
}

\begin{abstract}
Мета роботи: оцінка ефективності медичної практики клініки з огляду на ключові положення рекомендацій Американської тиреоїдної асоціації 2015 року, спрямованих на оптимізацію хірургічного лікування хворих із вузловими утворами щитоподібної залози.

Матеріали і методи. Проведення критичного аналізу окремих позицій настанов та рекомендацій Американської тиреоїдної асоціації редакції 2015 року. Ретроспективне дослідження із залученням 29 пацієнтів із цитологічно ідентифікованими випадками високодиференційованих карцином щитоподібної залози, яким були виконані оперативні втручання за період 20152018 рр. на базі хірургічного відділення Львівської клінічної лікарні на Залізничному транспорті.

Результати досліджень та їх обговорення. Клінічні ефекти оновленої версії рекомендацій Американської тиреоїдної асоціації є достатньо контраверсійні та не завжди знаходять одностайне схвалення з боку клініцистів (зокрема, вітчизняних шкіл із проблематики захворювань щитоподібної залози). Однією з можливих причин цього є розширення показань до виконання лобектомії (гемітиреоїдектомії) шляхом збільшення допустимих розмірів пухлини (в окремих ситуаціях до 4 см) та, відповідно, зменшення кількості хворих, яким виконано тиреоїдектомію (тотальну тиреоїдектомію). Тотальна тиреоїдектомія була здійснена у всіх пацієнтів нашої клініки, залучених до ретроспективного аналізу, що можна пояснити очікувано низьким рівнем комплаєнсу пацієнтів до тривалого спостереження. Водночас, тактика доопераційної підготовки, побудови та виконання діагностичного алгоритму та подальше ведення хворих у клініці загальної хірургії, в цілому, відповідали рекомендаціям та настановам Американської тиреоїдної асоціації редакції 2015 року. Виявлення вузла щитоподібної передбачає виконання багатокрокового алгоритму з метою встановлення характеру новоутворення, що має забезпечити формування оптимального плану лікування та подальшого спостереження. Наведені рекомендації, незважаючи на свою вичерпність, відіграють лише допоміжну роль для клініциста у прийнятті рішення, остаточно ж стратегія лікування вибудовується для кожного пацієнта індивідуально.
\end{abstract}

Ключові слова: щитоподібна залоза; карцинома щитоподібної залози; хірургічне лікування.

Постановка проблеми і аналіз останніх досліджень та публікацій. Протягом декількох останніх років з'являються численні публікації, дотичні лікуванню вузлових утворів та диференційованих форм раку щитоподібної залози (Щз). Системний підхід до визначення тактики лікування включає у себе проведення клінічної оцінки новоутворень, визначення сироваткових рівнів тиреотропного гормону, сонографічного сканування шиї та, за показаннями, тонкоголкової аспіраційної біопсії вузлів (ТАБ). Подальший алгоритм діагностики передбачає цитологічну верифікацію зразків із використанням принципів, визначених системою TBS (The Bethesda System), яка забезпечує ефективну комунікацію клініцистів та лабораторних діагностів 3 отриманням даних найвищого ступеня достовірності, які використовуються для національного та міжнародного статистичного аналізу. При верифікації раку ЩЗ необхідно визначити стадію процесу та оцінити можливі ризики для ефективності плану подальшого лікування [2, 3].
Вузлові утвори в ЩЗ є частою знахідкою при клінічному обстеженні пацієнтів. Основною метою подальшої діагностики $є$ вчасне виявлення малігнізації, при цьому інцидентність злоякісних новоутворень сягає, в середньому, до 10 \% [4].

Мета роботи: оцінка ефективності медичної практики клініки з огляду на ключові положення рекомендацій Американської тиреоїдної асоціації (ATA) 2015 року, спрямованих на удосконалення хірургічного лікування хворих із вузловими утворами ЩЗ .

Матеріали і методи. Проведення критичного аналізу окремих позицій настанов та рекомендацій АТА 2015 року. Ретроспективне дослідження стосувалося усіх пацієнтів із різноплановими захворюваннями Щ3, що перебували на стаціонарному лікування клініки загальної хірургії на базі хірургічного відділення Залізничної лікарні. Всього було опрацьовано 289 медичних карт стаціонарних хворих, нозологічний розподіл наведено у таблиці 1. 
Таблиця 1. Нозологічний розподіл випадків захворювання щз 2015-2018 рр.

\begin{tabular}{||l|c|c||}
\hline \hline Нозологічна форма & Абсолютна кількість хворих & 71,6 \\
\hline Нетоксичний вузловий зоб & 207 & 16,1 \\
\hline Хвороба Грейвса & 46 & 3,2 \\
\hline Автоімунний тиреоїдит & 10 & 8,9 \\
\hline Карцинома щитоподібної залози & 26 & 100 \\
\hline Всього & 289 & \\
\hline \hline
\end{tabular}

Серед усіх пацієнтів найбільший інтерес для дослідження представляли 26 осіб з цитологічно ідентифікованими випадками вискодиференційованих карцином ЩЗ, яким були виконані оперативні втручання за період 2015-2018 років. 326 випадків фолікулярна форма карциноми була виявлена у 15 \% пацієнтів (4 особи), папілярний рак був верифікований у більшості обстежених (22 особи, $85 \%)$.

Результати досліджень та їх обговорення. Останній опублікований консенсус АТА (2015) містить вичерпні клінічні рекомендації щодо побудови діагностичних та лікувальних алгоритмів при наявності тиреоїдних вузлів та диференційованого раку ЩЗ у дорослих пацієнтів [5]. Документ був складений на основі дворічного аналізу найсучасніших досліджень у цій царині та містить більше ста практичних настанов та рекомендацій, які спрямовані на вирішення клінічно складних питань тиреоїдології. Порівняно з попереднім виданням 2009 року, було внесено низку принципових змін та доповнень. Зокрема, був зроблений акцент на побудові лікувально-діагностичного алгоритму при безсимптомних вузлах ЩЗ, які виявляють пальпаторно чи випадково, при зверненні з приводу інших патологій. Після ретельної оцінки анамнестичних даних та загальноклінічних обстежень, визначення особливостей патоморфології вузлів потребує встановлення сироваткових рівнів тиреотропного гормону (ТТГ) та ультрасонографічну верифікації патологічних утворень [6].

Діагностичне значення сироваткових показників тиреоглобуліну та кальцитоніну, на первинних етапах, не доведене [5]. Вузли в поєднанні з низьким сироватковим рівнем ТТГ розглядають як показання для сканування ЩЗ з ізотопами ${ }^{123} \mathrm{I}$ або 99mТс. При виявленні “гарячих” вузлів, для яких здебільшого непритаманний злоякісний ріст, діагностичний пошук спрямовується на оцінку ступеня гіпертиреозу. “Холодні” вузли характеризуються 5 \% ймовірністю ідентифікації раку [6].
Ультрасонографія шиї, яка особливо показана при “холодних” вузлах, включає оцінку ЩЗ та шийних лімфатичних вузлів з одночасним вирішенням питання стосовно проведення ТАБ. Останню слід розглядати як процедуру вибору при діагностиці раку ЩЗ та діагностичним прийомом за високим ступенем рекомендації при вузлах, недоступних пальпації (розташованих у задніх відділах Щз) та вузлах з високим кістозним компонентом. Порівняно з рекомендаціями 2009 року суттєвих змін зазнали сонографічна оцінка вузлів та обгрунтування ТАБ [7]. У таблиці наведено новітню інтерпретацію домінуючих сонографічних знахідок з оцінкою ризику злоякісного росту та рекомендаціями стосовно ТАБ [8].

Багатовузлові ураження ЩЗ оцінюються подібно до вище наведених алгоритмів (див. табл. 2), при цьому кожний вузол підлягає індивідуальній клінічній оцінці. ТАБ доцільно поєднувати із системою TBS у цитологічній діагностиці зразків, що, у свою чергу, передбачає дотримання наступних рекомендацій [2, 5]:

1. При неінформативній цитології (ризик малігнізації 1-4 \%) доцільним є проведення повторного ТАБ під контролем сонографії з метою отримання відповідної інтерпретації зразків; повторні неінформативні цитологічні дослідження в поєднання із високим ступенем сонографічної підозри або клінічними ризиками малігнізації вимагає хірургічного втручання.

2. Доброякісна цитологія (ризик малігнізації 0-3 \%) - наступні дії визначаються групою ризику обстежуваних. Група високого ризику потребує повторної сонографії з ТАБ через рік, рекомендована лише сонографія для групи середнього ризику через 1-2 роки та понад 2 роки для групи низького ризику.

3. Атипія або фолікулярне ураження невизначеного цитологічного значення (ризик малігнізації 5-15 \%) - потребує оцінки кожного конкретного випадку на предмет спостереження, додаткової верифікації (у т. ч. молекулярні тести) чи оперативного втручання. 
Таблиця 2. Сонографічні прояви вузлів щз з оцінкою злоякісності та показами до ТАБ (наведено та модифіковано за American Thyroid association guidelines [2])

\begin{tabular}{||l|l|l||}
\hline \hline Ризик малігнізації & \multicolumn{1}{|c|}{ Дані сонографії } & \multicolumn{1}{|c|}{ Рекомендації за ТАБ } \\
\hline $70-90 \%$ & $\begin{array}{l}\text { Солідний гіпоехогенний вузол або солідно- } \\
\text { гіпоехогенні включення частково кістозного вузла 3 } \\
\text { одним або декількома компонентами: нерівні краї, } \\
\text { мікрокальцифікати, висота більше ширини }\end{array}$ & $\begin{array}{l}\text { Вузол понад 1 см (висока } \\
\text { рекомендація) }\end{array}$ \\
\hline $10-20 \%$ & $\begin{array}{l}\text { Гіпоехогенний солідний вузол без вагомих підозрілих } \\
\text { знахідок }\end{array}$ & $\begin{array}{l}\text { Вузол понад } 1 \text { см (висока } \\
\text { рекомендація) }\end{array}$ \\
\hline $5-10 \%$ & $\begin{array}{l}\text { Ізоехогенний або гіперехогенний солідний вузол } \\
\text { або частково (>50 \%) кістозний вузол з солідною } \\
\text { ділянкою без вагомих підозрілих знахідок }\end{array}$ & $\begin{array}{l}\text { Вузол понад 1,5 см (слабка } \\
\text { рекомендація) }\end{array}$ \\
\hline$<3 \%$ & $\begin{array}{l}\text { Губчастий або частково кістозний вузол без вагомих } \\
\text { підозрілих знахідок }\end{array}$ & $\begin{array}{l}\text { Вузол понад 2 см } \\
\text { (слабка рекомендація) } \\
\text { Вузол 1-2 см повторна } \\
\text { сонографія через 2 роки } \\
\text { Вузол менше 1 см - без } \\
\text { подальших дій }\end{array}$ \\
\hline$<1$ \% & Кістозні вузли без включень & $\begin{array}{l}\text { ТАБ не виконується } \\
\text { (висока рекомендація) } \\
\text { можлива аспірація для } \\
\text { комфорту }\end{array}$ \\
\hline
\end{tabular}

4. Фолікулярна неоплазія або підозра на неї (ризик малігнізації 15-30 \%) потребує хірургічного втручання або подальшого обстеження (молекулярні тести) у пацієнтів середнього та низького ризиків.

5. Підозра на цитологічну малігнізацію (ризик малігнізації 60-75 \%) - обов’ язкове хірургічне лікування.

6. Цитологічна малігнізація (ризик малігнізації 97-99 \%) - обов’ язкове хірургічне лікування.

Порівняно зі стандартом 2009 року, нові рекомендації спрямовані на більш стриманий підхід, з хірургічної точки зору, до невеликих вузлових утворень (до 1 см) та до вибору об’єму оперативного втручання (виконання лобектомії, а не тиреоїдектомії при пухлинах низького ступеня ризику). Тим не менше, саме оперативне лікування залишається “золотим стандартом” для подібної групи пацієнтів, що знайшло відображення в настановах 2015 року, згідно з якими хірургічний підхід має відповідати наступним рекомендаціям:

1. При пухлинах, розміром понад 4 см, а також при екстраорганному поширенні, віддалених та локальних метастазах, виконується тотальна (майже тотальна) тиреоїдектомія. Уніфокальні пухлини, розмірами 1-4 см без ознак метастазування потребують виконання лобектомії. У пацієнтів віком понад 45 років, високим хірургічним ризиком та сімейним анамнезом злоякісних новоутворень ЩЗ рекомендується проведення тотальної тиреоїдектомії; для пухли малого розміру (до 1 см) операцією вибору слід вважати лобектомію.

2. Тотальна тиреоїдектомія може бути запропонована пацієнтам, які попередньо перенесли лобектомію за умов несприятливого гістопатологічного діагнозу. Абляція радіоактивним йодом не може розглядатися як альтернатива хірургічному втручанню в подібних випадках [9].

3. Дисекція центральних та латеральних лімфовузлів доцільна за умов цитопатологічно доведеного злоякісного росту. Профілактична дисекція центральних вузлів не розглядається в якості рутинної процедури, особливо при відсутності належного об’єму клінічних досліджень. Водночас, окремі дослідники рекомендують виконувати згадане вище втручання у пацієнтів із папілярною карциномою ЩЗ та ураженням латеральних лімфатичних вузлів або у випадках заавансованого первинного процесу (стадії $\mathrm{T}_{3}$ або $\mathrm{T}_{4}$ ).

4. Окремі настанови акцентують увагу на важливість ідентифікації та збереження зворотного гортанного нерва, зовнішньої гілки верхнього гортанного нерва та прищитоподібних залоз із відповідними судинними стовбурами [10].

Клінічні ефекти оновленої версії рекомендацій ATA $є$ достатньо контраверсійними та не завжди 


\section{З ДОСВІДУ РОБОТИ}

знаходять одностайне схвалення з боку клініцистів (зокрема, вітчизняних шкіл тиреоїдології). Однією з можливих причин цього є розширення показань до виконання лобектомії шляхом збільшення допустимих розмірів пухлини (в окремих ситуаціях до 4 см) та, відповідно, зменшення числа хворих, яким показана тиреоїдектомія (тотальна тиреоїдектомія). Проте останній об’єм оперативного втручання був проведений у всіх досліджуваних пацієнтів нашої клініки, що можна пояснити очікувано низьким рівнем комплаєнсу пацієнтів до тривалого спостереження. Водночас тактика доопераційної підготовки, побудови та виконання діагностичного алгоритму та подальше ведення пацієнтів в клініці загальної хірургії в цілому відповідали рекомендаціям АТА 2015 року, що, ймовірно, дало змогу уникнути клінічно значимих ускладнень післяопераційного періоду.

Висновки. Опубліковані Американською тиреоїдною асоціацією у 2015 році нові рекомендації стосовно лікування вузлів ЩЗ та диференційованих форм раку ЩЗ базуються на достовірних даних численних клінічних досліджень з врахуванням думки провідних експертів галузі та даних літератури останніх років. Рутинне виявлення вузла ЩЗ передбачає виконання багатокрокового алгоритму 3 метою встановлення характеру новоутворення, що має за мету забезпечити формування реалістичного плану лікування та подальшого спостереження. Слід зауважити, що наведені рекомендації, незважаючи на свою вичерпність, відіграють лише допоміжну роль для клініциста у прийнятті оптимального рішення, остаточно ж стратегія лікування вибудовується для кожного пацієнта індивідуально.

Перспективи подальших досліджень. Більшість рекомендацій (в тому числі рекомендації ATA 2015 року) охоплюють лише найпоширеніші випадки і не можуть розглядатися в якості вичерпних правил для клінічної практики, а лише як узагальнюючі вказівки, що складені на основі вагомої доказової бази. На даний час, значною проблемою є існування великої кількості рекомендацій, стандартів і керівництв стосовно лікування пацієнтів із вузловими утворами та диференційованими формами раку ЩЗ. Незважаючи на формальну близькість подібних документів, існуючі між ними відмінності можуть спричинити ненавмисні неточності у прийнятті остаточних рішень клініцистами. Оскільки впровадження стандартизованих підходів до практики невпинно розвивається, вкрай бажаними є застосування уніфікованих принципів формування доказових баз.

\section{СПИСОК ЛІТЕРАТУРИ}

1. Less is more: the impact of multidisciplinary thyroid conference on the treatment of well-differentiated thyroid carcinoma / M. D. Moore, E. Postma, Gray K. D. [et al.] // World J. Surg. 2018. - Vol. 42 (2). - P. 343-349.

2. National Cancer Institute, American Society of Cytopathology: Bethesda System Website Atlas. http://nih.techriver.net/ (accessed May 9, 2017).

3. Cibas E. S. The Bethesda system for reporting thyroid cytopathology / E. S. Cibas, S. Z. Ali // Thyroid. - 2009. - Vol. 19 (11). - P. 1159-1165.

4. Thyroid ultrasound features and risk of carcinoma: a systematic review and meta-analysis of observational studies / L. R. Remonti, C. K. Kramer, C. B. Leitao [et al.] // Thyroid. - 2015. - Vol. 25 (5). - P. 538-550.

5. 2015 American Thyroid Association Management Guidelines for Adult Patients with Thyroid Nodules and Differentiated Thyroid Cancer: The American Thyroid Association Guidelines Task Force on Thyroid Nodules and Differentiated Thyroid Cancer / B. R. Haugen, E. K. Alexander, K. C. Bible [et al.] //
Thyroid. - 2016. - Vol. 26 (1). - P. 1-133.

6. Gharib H. Thyroid nodules: clinical importance, assessment and treatment / H. Gharib, E. Papini // Endocrinol. Metab. Clin. North Am. - 2007. - Vol. 36 (3). - P. 707-735.

7. Revised American Thyroid Association management guidelines for patients with thyroid nodules and differentiated. thyroid cancer / D. S. Cooper, G. M. Doherty, B. R. Haugen [et al.] // Thyroid. 2009. - Vol. 19 (11). - P. 1167-1214.

8. Anil G. Thyroid nodules: risk stratification for malignancy with ultrasound and guided biopsy / G. Anil, A. Hegde, F. H. Chong // Cancer Imaging. - 2011. - Vol. 11. - P. 209-223.

9. Oncologic outcomes after completion thyroidectomy for patients with well-differentiated thyroid carcinoma / B. R. Untch, F. L. Palmer, I. Ganly [et al.] // Ann. Surg. Oncol. - 2014. Vol. 21 (4). - P. 1374-1378.

10. Clinical practice guideline: improving voice outcomes after thyroid surgery / S. S. Chandrasekhar, G. W. Randolph, M. D. Seidman [et al.] // Otolaryngol. Head Neck Surg. - 2013. Vol. 148 (Suppl. 6). - P. S1-37

\section{REFERENCES}

1. Moore, M.D., Postma, E., \& Gray, K.D. (2018). Less is more: the impact of multidisciplinary thyroid conference on the treatment of well-differentiated thyroid carcinoma. World $J$. Surg., 42 (2), 343-349.
2. National Cancer Institute, American Society of Cytopathology. Bethesda System Website Atlas. Retrieved from: http://nih. techriver.net/ (accessed May 9, 2017).

3. Cibas, E.S., \& Ali, S.Z. (2009). The Bethesda system for 
reporting thyroid cytopathology. Thyroid, 19 (11), 1159-1165. 4. Remonti, L.R., Kramer, C.K., \& Leitao, C.B. (2015). Thyroid ultrasound features and risk of carcinoma: a systematic review and meta-analysis of observational studies. Thyroid, 25 (5), 538550 .

5. Haugen, B.R., Alexander, E.K., \& Bible, K.C. (2016). 2015 American Thyroid Association Management Guidelines for Adult Patients with Thyroid Nodules and Differentiated Thyroid Cancer: The American Thyroid Association Guidelines Task Force on Thyroid Nodules and Differentiated Thyroid Cancer. Thyroid, 26 (1), 1-133.

6. Gharib, H., \& Papini, E. (2007). Thyroid nodules: clinical importance, assessment and treatment. Endocrinol. Metab. Clin. North Am., 36 (3), 707-735.
7. Cooper, D.S., Doherty, G.M., \& Haugen, B.R. (2009). Revised American Thyroid Association management guidelines for patients with thyroid nodules and differentiated. thyroid cancer. Thyroid, 19, (11), 1167-1214.

8. Anil, G., Hegde, A., \& Chong, F.H. (2011). Thyroid nodules: risk stratification for malignancy with ultrasound and guided biopsy. Cancer Imaging, 11, 209-223.

9. Untch, B.R., Palmer, F.L., \& Ganly, I. (2014). Oncologic outcomes after completion thyroidectomy for patients with well-differentiated thyroid carcinoma. Ann. Surg. Oncol., 21 (4), 1374-1378.

10. Chandrasekhar, S.S., Randolph, G.W., \& Seidman, M.D. (2013). Clinical practice guideline: improving voice outcomes after thyroid surgery. Otolaryngol. Head Neck Surg., 148 (6 Suppl.), S1-37.

Отримано 17.10.2019

Електронна адреса для листування: kyryk_taras@meduniv.lviv.ua

T. P. KYRYK ${ }^{1}$, V. V. VASHCHUK ${ }^{1}$, M. I. KUSHNIRCHUK², R. P. BAYDALA ${ }^{2}$, M. M. SYMO ${ }^{2}$

Danylo Halytskyi Lviv National Medical University ${ }^{1}$

Lviv Clinical Hospital at the JSC "Ukrainian Railways" of the branch "Health Center"2

\section{EXPERIENCE OF IMPLEMENTATION OF THE AMERICAN THYROID ASSOCIATION CONSENSUS STANDARDS AT THE GENERAL SURGERY CLINIC AT LVIV CLINICAL HOSPITAL ATJSG "UKRAINIAN RAILWAYS" OF THE HEALTH CENTER BRANCH}

The aim of the work: evaluation of the effectiveness of the clinic's medical practice in view of the key provisions of the 2015 American Thyroid Association recommendations aimed at optimizing the surgical treatment of patients with thyroid nodules.

Materials and Methods. Carrying out a critical analysis of the individual positions and guidelines of the 2015 American Thyroid Association. A retrospective study involving 29 patients with cytologically identified cases of viscerally differentiated thyroid carcinoma who underwent surgery for the period 2015-2018 at the Surgical Department of the Lviv Clinical Hospital on Railway Transport.

Results and Discussion. The clinical effects of the updated version of the recommendations of the American Thyroid Association are controversial enough and do not always find unanimous approval from clinicians (in particular, national schools on thyroid disease). One of the possible reasons for this is the extension of indications for lobectomy (hemithyroidectomy) by increasing the admissible tumor size (in some situations up to $4 \mathrm{~cm}$ ) and, accordingly, reducing the number of patients undergoing thyroidectomy (total thyroidectomy). Total thyroidectomy was performed in all patients in our clinic who were involved in retrospective analysis, which can be explained by the expected low level of patient compliance for long-term follow-up. At the same time, the tactics of preoperative preparation, construction and execution of the diagnostic algorithm and the subsequent management of patients in the General Surgery Clinic, in general, were in line with the recommendations and guidelines of the American Thyroid Association 2015 edition. Detection of the thyroid node involves the implementation of a multi-step algorithm to determine the nature of the neoplasm, which should ensure the formation of an optimal treatment plan and follow-up. The recommendations given, despite their comprehensiveness, play only ancillary role for the clinician in decision making, and finally, a treatment strategy is built for each patient individually.

Key words: thyroid; thyroid carcinoma; surgical treatment. 


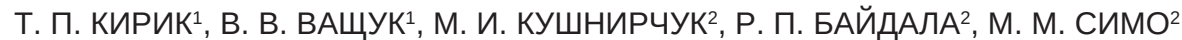

Львовский национальный медицинский университет имени Данила Галицкого

Львовская клиническая больница на ВТ ПАО "Украинская железная дорога" орилиала "Центр охраны здоровья"2

\section{ОПЫТ ПРИМЕНЕНИЯ СТАНДАРТОВ КОНСЕНСУСА АМЕРИКАНСКОЙ ТИРЕОИДНОЙ АССОЦИАЦИИ В КЛИНИКЕ ОБЩЕЙ ХИРУРГИИ НА БАЗЕ ЛЬВОВСКОЙ КЛИНИЧЕСКОЙ БОЛЬНИЦЫ НА ВТ ПАО “УКРАИНСКАЯ ЖЕЛЕЗНАЯ ДОРОГА” ФИЛИАЛА "ЦЕНТР ОХРАНЫ ЗДОРОВБЯ"}

Цель работы: оценка эффективности медицинской практики клиники учитывая ключевые положения рекомендаций Американской тиреоидной ассоциации 2015 года, направленных на оптимизацию хирургического лечения больных с узловыми образованиями щитовидной железы.

Материалы и методы. Проведение критического анализа отдельных позиций установок и рекомендаций Американской тиреоидной ассоциации редакции 2015 года. Ретроспективное исследование с привлечением 29 пациентов с цитологически идентифицированными случаями високодифференцированных карцином щитовидной железы, которым были выполнены оперативные вмешательства за период 2015-2018 гг. на базе хирургического отделения Львовской клинической больницы на Железнодорожном транспорте.

Результаты исследований и их обсуждение. Клинические эффекты обновленной версии рекомендаций Американской тиреоидной ассоциации достаточно контраверсионные и не всегда находят единодушное одобрение со стороны клиницистов (в частности, отечественных школ по проблематике заболеваний щитовидной железы). Одной из возможных причин этого является расширение показаний к выполнению лобэктомии (гемитиреоидэктомию) путем увеличения допустимых размеров опухоли (в отдельных ситуациях до 4 см) и, соответственно, уменьшение количества больных, которым выполнено тиреоидэктомию (тотальную тиреоидэктомию). Тотальная тиреоидэктомия была осуществлена у всех пациентов нашей клиники, вовлеченных в ретроспективный анализ, можно объяснить ожидаемо низким уровнем комплаенса пациентов к длительному наблюдению. В то же время, тактика предоперационной подготовки, построения и выполнения диагностического алгоритма и дальнейшее ведение больных в клинике общей хирургии, в целом, соответствовали рекомендациям и установкам Американской тиреоидной ассоциации редакции 2015 года. Выявление узла щитовидной железы предусматривает выполнение многошагового алгоритма с целью установления характера новообразования, что должно обеспечить формирование оптимального плана лечения и дальнейшего наблюдения. Приведены рекомендации, несмотря на свою полноту, играют лишь вспомогательную роль для клинициста в принятии решения, окончательно стратегия лечения выстраивается для каждого пациента индивидуально.

Ключевые слова: щитовидная железа; карцинома щитовидной железы; хирургическое лечение. 